\title{
Disturbances in metabolic, transport and structural genes in experimental colonic inflammation in the rat: a longitudinal genomic analysis
} Olga Martínez-Augustin1, Manel Merlos², Antonio Zarzuelo ${ }^{3}$, María Dolores Suárez ${ }^{1}$ and Fermín Sánchez de Medina*3

Address: ${ }^{1}$ Department of Biochemistry and Molecular Biology II, CIBEREHD, School of Pharmacy, University of Granada, Campus de Cartuja s/ n, 18071 Granada, Spain, 2Palau Pharma, Pol. Ind. Riera de Caldes Avinguda Camí Reial 51-57, 08184 Palau-solità i Plegamans, Barcelona, Spain and ${ }^{3}$ Department of Pharmacology, CIBEREHD, School of Pharmacy, University of Granada, Campus de Cartuja s/n, 18071 Granada, Spain

Email: Olga Martínez-Augustin - omartine@ugr.es; Manel Merlos - pharm.merlos@uriach.com; Antonio Zarzuelo - zarzuelo@ugr.es; María Dolores Suárez - msuarez@ugr.es; Fermín Sánchez de Medina* - fsanchez@ugr.es

* Corresponding author

Published: 17 October 2008

BMC Genomics 2008, 9:490 doi:10.1 |86/|47|-2164-9-490
Received: 9 May 2008

Accepted: 17 October 2008

This article is available from: http://www.biomedcentral.com/I47I-2/64/9/490

(c) 2008 Martínez-Augustin et al; licensee BioMed Central Ltd.

This is an Open Access article distributed under the terms of the Creative Commons Attribution License (http://creativecommons.org/licenses/by/2.0), which permits unrestricted use, distribution, and reproduction in any medium, provided the original work is properly cited.

\begin{abstract}
Background: Trinitrobenzenesulphonic acid (TNBS) induced rat colitis is one of the most widely used models of inflammatory bowel disease (IBD), a condition whose aetiology and pathophysiology are incompletely understood. We have characterized this model at the genomic level using a longitudinal approach. Six control rats were compared with colitic animals at 2, 5, 7 and I 4 days after TNBS administration $(n=3)$. The Affymetrix Rat Expression Array 2302.0 system was used.

Results: TNBS-induced colitis had a profound impact on the gene expression profile, which was maximal 5 and 7 days post-induction. Most genes were affected at more than one time point. They were related to a number of biological functions, not only inflammation/immunity but also transport, metabolism, signal transduction, tissue remodeling and angiogenesis. Gene changes generally correlated with the severity of colitis. The results were successfully validated in a subset of genes by real-time PCR.

Conclusion: The TNBS model of rat colitis has been described in detail at the transcriptome level. The changes observed correlate with pathophysiological disturbances such as tissue remodelling and alterations in ion transport, which are characteristic of both this model and IBD.
\end{abstract}

\section{Background}

Inflammatory bowel disease (IBD), comprising ulcerative colitis and Crohn's disease, is characterized by chronic and relapsing inflammation of the gastrointestinal tract. The pathogenesis of IBD is unknown, but it appears to be multifactorial in origin, and genetic, environmental and dietary factors are believed to be involved [1]. Animal models of IBD have been central to the investigation of the pathophysiology of the disease and are valuable tools for drug testing and development. Because IBD-like diseases do not occur spontaneously in animals, several animal models that mimic different aspects of the disease are currently used, including gene knockout, transgenic, chemical, adoptive transfer and spontaneous models [2]. 
To date, no single model has reproduced all features of the human disease. One of the most widely used models in both pharmacological and pathophysiological studies (72 in the past year) is murine colitis induced by trinitrobenzenesulphonic acid (TNBS) [3-5]. This simple model is based on a single rectal administration of TNBS dissolved in ethanol. TNBS is a hapten that elicits an immune response when bound to tissue proteins, while ethanol contributes to disruption of the intestinal barrier. The result is a severe and prolonged degenerative inflammation of large parts of the colon sharing several clinical and molecular characteristics with Crohn's disease. Specifically, the inflammation produced by the administration of TNBS-ethanol involves all layers of the intestinal mucosa and produces long-lasting damage with cell infiltration and ulcers, including protracted physiological dysfunction. Furthermore, both TNBS-ethanol administration to mice and human Crohn's disease are characterized by Th1-driven inflammation with infiltration of macrophages and neutrophils, producing high levels of proinflammatory cytokines such as tumour necrosis factor, interleukin (IL)-1 $\beta$ and IL-6, followed by T cell infiltration, mainly of the CD4+ phenotype.

Genomic profiling of disease models is of interest for characterizing the pathological response at transcriptome level and identifying putative drug targets. Animal models may overcome many of the limitations of the application of genomic technology to humans, including the need for repeated encoscopy, the large genetic and phenotypic variability, and the difficulty of studying the initial stages of the disease. There have been a few attempts at gene expression profiling in IBD models [6-10]. In general, these studies have addressed acute colitis (48-72 $\mathrm{h}$ after induction), employed small microarrays (containing 87 and 1252 transcripts in two of the studies), have analysed large samples (augmenting internal genomic variation, which occurs along the longitudinal axis) and include modest validation experiments (6-14 genes). Although a recent study by te Velde et al. [8] used 20,000 transcript microarrays, the data were not validated. Only one of the studies was longitudinal [9]. Therefore, the present study represents the most ambitious and comprehensive investigation to date, using several microarrays to examine the progression of colitis at four time points, employing a genechip platform that includes more than 30,000 transcripts (Affymetrix Rat 230 2.0). Results were validated in a subset of almost 100 transcripts by using real-time PCR (qRT-PCR). The full results database, publicly accessible, will serve as a valuable reference for all researchers in the field. In fact, three pharmacological studies adopting this strategy are currently underway in our laboratory.

\section{Methods}

All reagents were obtained from Sigma (Barcelona, Spain) except where indicated.

\section{Animals}

Female Wistar rats (175-225 g) were used, housed in makrolon cages and maintained in air-conditioned animal quarters with a 12-h light-dark cycle. Animals had free access to tap water and were fed a standard chow diet (Panlab A04, Panlab, Barcelona, Spain). This study was carried out in accordance with the Directive for the Protection of Vertebrate Animals used for Experimental and other Scientific Purposes of the European Union (86/609/ EEC), was approved by the Ethical Committee of the University of Granada and complies with the American Physiological Society's Guiding Principles in the Care and Use of Animals.

\section{Induction of colitis}

Colitis was induced as previously described [11]. Briefly, rats were fasted overnight and anaesthetized with halothane. Under these conditions, rats were given $10 \mathrm{mg}$ of TNBS dissolved in $0.25 \mathrm{ml}$ of $50 \%$ ethanol (v/v) by means of a Teflon cannula inserted $8 \mathrm{~cm}$ into the anus. Rats were kept in a head-down position for an additional $30 \mathrm{~s}$ and returned to their cages.

\section{Experimental design}

Rats were randomly assigned to one of two different groups, a control $(\mathrm{C}, \mathrm{n}=6)$ group that received a saline enema and a TNBS group $(n=12)$ that received the TNBS challenge. Food and water intake and body weight were determined daily. To follow the progression of the colitis, three rats of the TNBS group were killed 2, 5, 7 and 14 days after the induction of colitis. Three control rats were killed on day 2 and the other three at the end (day 14) of the experiment. For the purpose of postgenomic validation, this experiment was repeated in order to perform qRT-PCR analysis on fresh samples. The magnitude and time course of the inflammatory response were similar in both experiments (data not shown).

\section{Assessment of colonic damage}

Animals were killed by cervical dislocation, and the entire colon was removed and placed on an ice-cold plate, cleaned of fat and mesentery, and blotted on filter paper. Each specimen was weighed and its length measured under a constant load ( $2 \mathrm{~g}$ ). The large intestine was longitudinally opened and scored for visible damage on a 0 to 25 scale as previously described [12]. A sample for genomic analysis was obtained from the distal colon approximately $4.5 \mathrm{~cm}$ proximal to the anus, taking care to avoid any areas of necrosis. The colon was subsequently divided longitudinally into several pieces for biochemical determinations. The fragments were immediately frozen in liquid nitrogen and kept at $-80^{\circ} \mathrm{C}$ until used. Myeloperoxidase activity was measured according to the technique described by Krawisz et al. [13]. 


\section{RNA extraction, microarray hybridization and data analysis}

RNA was extracted from homogenized full-thickness colonic tissues in Trizol ${ }^{\circledR}$ reagent (Invitrogen) and purified with RNeasy affinity columns (Qiagen). Quantity and integrity of RNA were assessed by spectrophotometry and $0.8 \%$ agarose gel electrophoresis, respectively. Sample labelling, hybridization, staining and scanning procedures were carried out using Affymetrix standard protocols http://www.affymetrix.com. The microarray analysis was performed by Progenika Biopharma (Bilbao, Spain) on 18 GeneChip ${ }^{\circledR}$ Rat Expression Array 2302.0 microchips (Affymetrix). Normalization and statistical analyses were carried out using GeneSpring v7.1 (Agilent). Gene ontology analysis was performed with GeneMapp/MappFinder http://www.genmapp.org[14]. Specifically, biological process, cellular component and molecular function categories were scored with respect to the number of genes included in the Rattus norvegicus database that were measured in the microarray and the number of genes significantly affected by TNBS colitis in each category. The resulting $\mathrm{z}$ parameter [15] has positive values when the proportion of genes affected is higher than expected, and it was used to select the most representative gene ontology categories (i.e. those with $z \geq 4$ ) at each time point. Nonredundant categories are shown, listing only the highest $z$ value when nested categories exceeded the cutoff value at multiple levels. The k-means algorithm was applied to identify and group transcript changes over time in clusters. Only sequences with annotated gene identities that were present (intensity > 100 units) in at least $66 \%$ of samples per group in at least one group were considered. The data were analyzed by analysis of variance followed by Tukey post-hoc tests in order to reduce the false positive or type I error rate in inter-group comparisons. In addition, the Benjamini \& Hochberg false discovery rate correction was applied to reduce the occurrence of type I error when comparing among genes. This procedure offers a reasonable balance between sensitivity and specificity. Data are expressed as fold change (mean \pm SEM) over the control (uninflamed) group $(n=6)$ at each time point (TNBS colitis after 2, 5, 7 or 14 days). MIAME recommendations [16] were followed to ensure that all information needed to understand, interpret, reproduce and compare our results was given in detail. The data are accessible at the the European Bioinformatics Institute Arrayexpress database (http://www.ebi.ac.uk, reference E-MEXP-873).

\section{Postgenomic validation}

Postgenomic validation was carried out by measuring 93 of the genes in fresh samples ( $n=3$ per group) using qRTPCR with TaqMan ${ }^{\circledR}$ Low Density Arrays (Applied Biosystems). Genes were selected to include both significantly and non-significantly changed genes pertaining to different families affected by inflammation, i.e., those related to transport, immunity or metabolism. The relative Ct values of each gene with respect to the reference gene (18S) were used to calculate the RQ (relative quantitation) parameter, which represents the change in mRNA expression compared to a control sample. The RQ was then used to calculate fold change ratios. Results are expressed as mean \pm SEM.

\section{Results \\ TNBS colitis}

The morphological and biochemical features of TNBS colitis were consistent with previous reports by our group and other authors $[4,5,12,17]$. Thus, TNBS-treated rats suffered anorexia and loss of body weight (Fig. 1) associated with extensive mucosal damage, oedema, haemorrhage and early epithelial necrosis. Leukocyte infiltration was prominent, resulting in a significant increase in myeloperoxidase activity (Fig. 1). Epithelial regeneration gradually occurred from day 7 and was macroscopically complete by day 14. At 5 and 7 days, there was major submucosal fibrosis and scarring that resulted in a marked shortening of colonic length. Even after 2 weeks, treated rats showed significant differences with controls in colonic weight-to-length ratio and myeloperoxidase activity, among others (Fig. 1).

\section{Genomic analysis}

2340 genes were significantly modified at 2 days after TNBS instillation (1238 upregulated, 1102 downregulated). This number was almost doubled at day 5 (4266, 2073 of which were upregulated) and rose to 5752 (2356 upregulated) by day 7 . The pool of altered gene expression

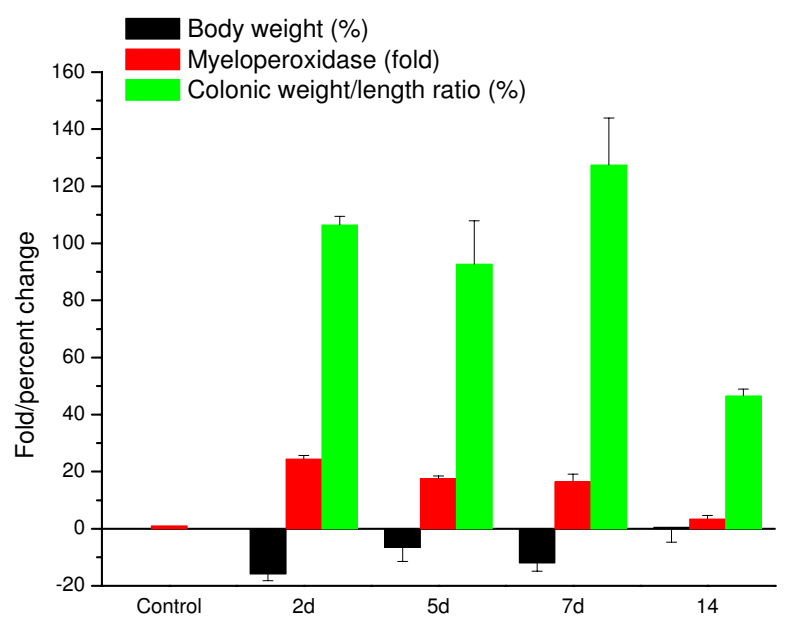

Figure I

Inflammatory biochemical and morphological markers in TNBS-induced colitis. All means were different from the control values, except for body weight gain at 14 days (not shown). 
fell to 1953 by day 14 (1146 upregulated), coinciding with a marked recovery from the inflammatory bout. The dendogram in Figure 2 shows that samples from TNBS colitic rats at each time point were clustered together, forming groups that significantly differed from control samples. As expected, many of the genes that showed significant changes are directly related to the inflammatory response, including genes for chemokines, cytokines and inflammatory markers such as Cp, Ptgs2, or Lyz (see below).

An additional set of three rats per experimental group was subjected to confirmatory analysis of 93 genes by qRTPCR. This independent validation procedure for microarray analysis results has become standard in genomic studies, although our use of triplicate measurements may have made this step redundant. An excellent correlation was found between microarray and qRT-PCR data (0.89 regression coefficient, $\mathrm{n}=1116$, Fig. 3 ). Individual examples can be seen in other Figures (see below). Amplification was not possible with two of the selected genes, namely Defb1 and Htr6. In addition, neither Il6 nor Ifng could be detected in the control samples but both were measured in the colitis groups. Hence, although this is an unmistakable indication of significant induction, a fold change could not be calculated from the qRT-PCR data. The reason for this discrepancy is not known.

Table 1 shows some of the most relevant gene categories affected by TNBS colitis (pre-established gene ontology entries), which differed according to the time point during the inflammatory response. Thus, although the immune response categories predictably dominated at all time points, apoptosis appeared to play a pivotal role at days 2

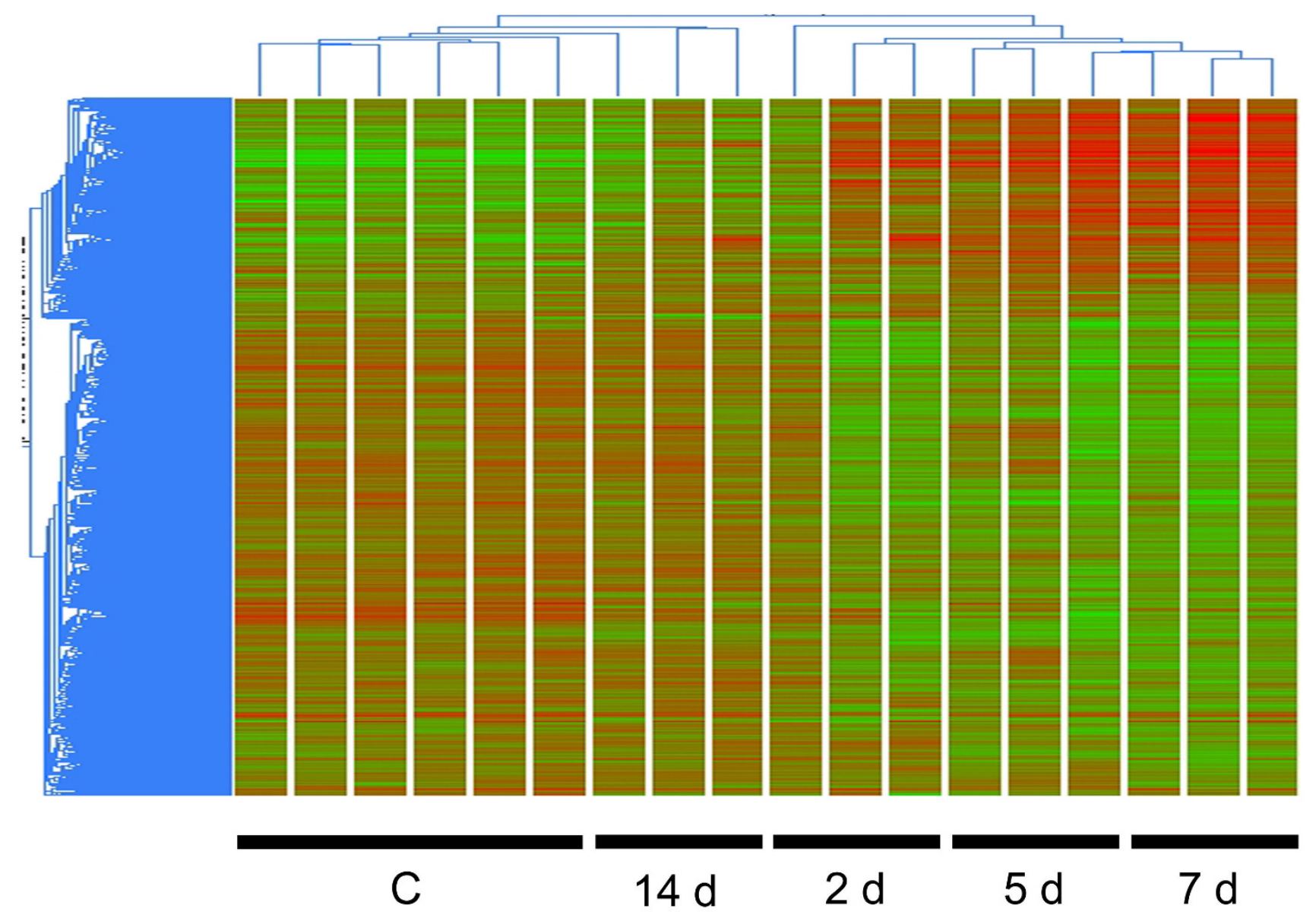

Figure 2

Time course changes of gene expression in rat TNBS colitis. Sample clustering by two-way analysis of variance. Upregulated genes are shown in red and downregulated genes in green. The difference between TNBS colitis and control samples was greatest on day 7. 


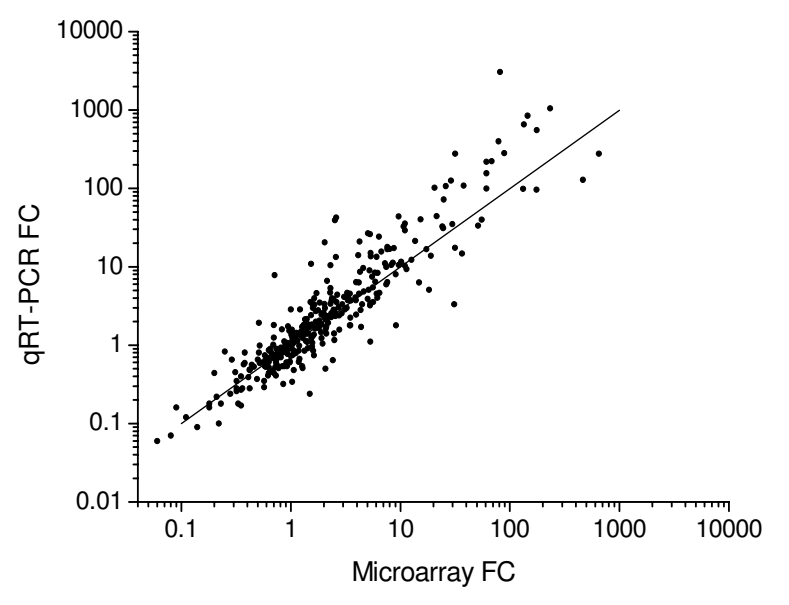

Figure 3

Postgenomic validation of microarray data. Correspondence between mean fold change $(F C)$ values obtained by microarray $(\mathrm{X})$ and $\mathrm{qRT}$-PCR $(\mathrm{Y})$ analysis. The diagonal line represents the ideal correspondence trend.

and 5 while extracellular matrix related genes were especially important at day 7 , and a variety of processes and functions were present as leading gene ontology categories at day 14. Manual analysis of the genes showing the most pronounced changes in expression confirmed the importance of immunity/inflammation and tissue remodelling/matrix but also indicated the occurrence of wide changes in transport, metabolism and signalling (see below).

\section{Time course analysis}

The set of genes that was significantly altered by TNBS colitis underwent k-means clustering, a mathematical tool that groups genes with a similar time evolution profile. Most genes clustered to profiles that showed the highest increase (or decrease) at 5 and 7 days, usually peaking at 7 days or staying relatively constant between 2 and 7 days and decreasing or increasing at 14 days (data not shown). However, some atypical profiles were also detected. Thus, the expression of some genes was changed only at day 2 (50 genes, Table 2 ) or day 14 (57 genes, Table 3 ) while others were upregulated (Cybb, Nfil3, Cxcr4, Spn, Itgb2) or downregulated (Apob, Amn, Apoa1, Aldob, Cxcl14, Ckm, Slc26a3) at all or most time points. Therefore, somewhat unexpectedly, the time course of gene expression was largely parallel, with few outliers, although there were marked differences in the magnitude of changes. However, as explained above, there was a change over time in the clustering of gene groups according to gene ontology.

\section{Genes involved in the inflammatory response}

Many of the most severely affected genes were those directly involved in the inflammatory response, as expected (Fig. 4, see also Fig. 5 for validated genes). Chemokines were especially prominent, including neutrophil chemokines and other leukocyte-attractant molecules. Interleukin 1 and related TLR2 pathways were highly affected, and both converged in the activation of NF- $\kappa B$. Nfkbia (encoding IкB- $\alpha$ ) was markedly increased, indicating a trend to limit activation of this pathway. The intestinal inflammatory marker Alpl [18] was prominently upregulated, unlike Alpi and Alpi2, the intestinal isoforms of alkaline phosphatase (data not shown).

The prostaglandin biosynthetic pathway was strongly activated by TNBS through the concerted induction of Pla2g2a, Ptgs2, and Ptges, especially during the chronic phase (confirmed by qRT-PCR, data not shown). Other affected genes are related to cell adhesion, bacteria binding or reactive oxygen species generation. There were also marked changes in the expression of numerous transcripts involved in antioxidative defence, most of which were downregulated.

In addition, close examination of the expression level of a number of genes that act as inflammatory cell markers indicated the nature of the inflammatory infiltrate. Thus, TNBS colitis was characterized by an absence of significant changes in markers of T cells (Thy1, Tcrb, Tcrg, Zap70, Lck), B cells (Ptprc -B220-, Ms4a1 -Cd20-, Cd22, Cd79b) and NK cells (Baat, Ncam1 -Cd56-, B3gat1 -Cd57-). In contrast, several neutrophil/macrophage markers such as S100a8, Itgb2 (Cd18), Cd68_predicted, Csf1r, Cybb, Csf2rb1 and Lcn2 were significantly increased by inflammation, especially at days 5 and 7.

\section{Genes involved in metabolism}

Metabolism-related genes were highly affected (mostly decreased) by TNBS-induced colitis (Fig. 6 and also Fig. 7 for validated genes). They included genes participating in glycolysis, like Aldob and many different subunits of the pyruvate dehydrogenase complex (Dlat, Dld, Pdha1, Pdhb). Several enzymes of the Krebs cycle were also changed, e.g., Idh3g, Aco2, Sucla2 and Cs. The respiratory chain genes Ndufs 1 and Sdhc and several genes encoding cytochrome isoforms were also downregulated.

With regard to lipid metabolism, the fatty acid biosynthetic enzymes Fasn and Scd1 were inhibited, as was the related gene Acly. Several transcripts related to cholesterol biosynthesis and transport were also affected (Hmgcr, Srebf1, Bzrp, Dhcr7, Dhcr24, Apoa1, Abca1). In addition, both ApoE and the apolipoprotein B mRNA editing gene Apobec1 were upregulated, suggesting a higher lipopro- 
Table I: Gene ontology categories most affected by TNBS colitis at different time points

\begin{tabular}{|c|c|c|c|}
\hline & & Gene ontology category & $z$ value \\
\hline \multirow[t]{6}{*}{ Day 2} & Biological process & Positive regulation of anti-apoptosis & 5.033 \\
\hline & & Leukocyte chemotaxis & 5.199 \\
\hline & Cellular component & Phosphoinositide 3-kinase complex & 4.202 \\
\hline & Molecular function & Chemokine activity & 5.721 \\
\hline & & I-Phosphatidylinositol 3-kinase activity & 4.582 \\
\hline & & Unfolded protein binding & 4.022 \\
\hline \multirow[t]{29}{*}{ Day 5} & Biological process & Immune system process & 6.507 \\
\hline & & Immune response & 6.088 \\
\hline & & Defence response & 6.025 \\
\hline & & Response to external stimulus & 5.402 \\
\hline & & Antigen processing and presentation of peptide antigen via $\mathrm{MHC}$ class II & 5.128 \\
\hline & & Lymphocyte mediated immunity & 4.962 \\
\hline & & Cell death & 4.910 \\
\hline & & Response to other organism & 4.532 \\
\hline & & Leukocyte migration & 4.506 \\
\hline & & Cytokine biosynthetic process & 4.484 \\
\hline & & Phagocytosis, recognition & 4.473 \\
\hline & & Positive regulation of lymphocyte differentiation & 4.348 \\
\hline & & Vasculature development & 4.320 \\
\hline & & Protein amino acid dephosphorylation & 4.289 \\
\hline & & Regulation of inflammatory response & 4.190 \\
\hline & & $\mathrm{T}$ cell differentiation & 4.091 \\
\hline & & Peptide antigen transport & 4.044 \\
\hline & & Regulation of protein binding & 4.001 \\
\hline & & Organelle fusion & 4.001 \\
\hline & Cellular component & MHC class II protein complex & 4.900 \\
\hline & & Mitochondrial respiratory chain & 4.384 \\
\hline & & TAP complex & 4.374 \\
\hline & Molecular function & Haematopoietin/interferon-class (D200-domain) cytokine receptor activity & 5.107 \\
\hline & & Protein tyrosine phosphatase activity & 4.871 \\
\hline & & Cytokine activity & 4.600 \\
\hline & & Chemokine activity & 4.277 \\
\hline & & NADH dehydrogenase activity & 4.133 \\
\hline & & Peptide antigen-transporting ATPase activity & 4.044 \\
\hline & & Phosphatidylserine binding & 4.001 \\
\hline \multirow[t]{10}{*}{ Day 7} & Biological process & Leukocyte chemotaxis & 4.936 \\
\hline & & Immune system process & 4.332 \\
\hline & & Response to external stimulus & 4.323 \\
\hline & & Antigen processing and presentation of exogenous peptide antigen & 4.124 \\
\hline & Cellular component & Extracellular matrix part & 5.849 \\
\hline & & Proteinaceus extracellular matrix & 4.931 \\
\hline & & Collagen & 4.674 \\
\hline & & Basement membrane & 4.280 \\
\hline & & Actin filament & 4.115 \\
\hline & Molecular function & Extracellular matrix constituent & 4.710 \\
\hline \multirow[t]{11}{*}{ Day 14} & Biological process & Defence response & 5.420 \\
\hline & & Prophyrin catabolic process & 5.286 \\
\hline & & Immune response & 5.082 \\
\hline & & Lymphocyte homeostasis & 5.029 \\
\hline & & DNA damage response, signal transduction by $\mathrm{p} 53$ class mediator & 4.414 \\
\hline & & Glial cell migration & 4.414 \\
\hline & & Leukocyte activation & 4.366 \\
\hline & & Inflammatory response & 4.362 \\
\hline & & RNA destabilization & 4.316 \\
\hline & & Positive regulation of interferon-gamma production & 4.316 \\
\hline & & Heme oxidation & 4.316 \\
\hline
\end{tabular}


Table I: Gene ontology categories most affected by TNBS colitis at different time points (Continued)

\begin{tabular}{lll}
\hline & Vasodilation & 4.231 \\
& Cytokine biosynthetic process & 4.142 \\
Cellular component & External side of plasma membrane & 5.339 \\
& Costamere & 4.316 \\
& B cell receptor complex & 4.316 \\
& Double-stranded DNA adenosine deaminase activity & 5.286 \\
Molecular function & Interleukin I, Type I receptor binding & 4.316 \\
& DNA ligase (ATP) activity & 4.316 \\
& Heme oxygenase (decyclizing) activity & 4.316 \\
& Saccharopine dehydrogenase (NAD+, L-glutamate-forming) activity & 4.316 \\
& Thyroid hormone receptor activity & 4.316 \\
& Cannabinoid receptor activity & 4.316 \\
\hline
\end{tabular}

Non-redundant categories with $\mathrm{z}$ values $>4$ are shown. A high $\mathrm{z}$ value indicates a higher representation of significantly changed genes than expected.

tein biosynthesis, although ApoE may also play a protective role against lipopolysaccharide [19]. A number of other metabolic pathways appeared to be altered by TNBS colitis, including purine de novo biosynthesis, arginine and heme catabolism.

\section{Genes involved in signalling}

Many transcripts involved in cell signalling were changed by TNBS colitis, including genes encoding proteins that participate in CAMP/protein kinase A and calcium/protein kinase $\mathrm{C}$ pathways, phosphatases, various regulatory proteins and a number of transmitter/hormone receptors, including P2ry6, Htr2b, Prlr, Sstr1, Tacr2 and Thra. In addition, Ace was modestly increased only on day 14, suggesting a possible local increase in angiotensin II production in the healing colonic tissue (Fig. 8).

The signalling-related genes that exhibited the highest changes in expression included Gp49b and Plek. Gp49b encodes an immunoglobulin-like receptor expressed in myeloid cells that appears to counter-regulate the cytokine and chemokine attraction of neutrophils [20]. The function of Plek appears to be related to the regulation of macrophage phagocytosis [21].

\section{Genes involved in transport}

TNBS colitis influenced the expression of many transportrelated transcripts, including genes that participate in ionic transport, e.g. Slc9a2, Slc9a3 (Nhe2-3), Scnn1a and Slc26a3 (Dra), which mediate $\mathrm{NaCl}$ absorption, and the $\mathrm{Na}^{+} / \mathrm{K}^{+}$pump subunit Atp1a1 and Slc12a2 (Nkcc2), all of which were inhibited. However, the chloride channel Cftr was not affected. Three aquaporins (Aqp3, 8 and 11) were also repressed in TNBS colitis, whereas Aqp9 was upregulated. Many other nonionic transporters and ionic channels were altered (Fig. 9 and Fig. 10 for validated genes). Interestingly, there was upregulation of Slc7a7, which is involved in the basolateral transport of arginine, lysine and ornithine by epithelial cells and activated monocytes [22], suggesting increased availability of iNOS substrate.

\section{Genes involved in tissue remodelling}

Following the gene ontology analysis, a manual search of the most severely affected genes confirmed the dramatic changes in the expression of many genes involved in matrix deposition, muscle plasticity and angiogenesis (see Figs. 11 and 12 for validated genes). These include Igf1 (validated) and Igfbp5, genes that may regulate tissue remodelling by increasing collagen synthesis and cell proliferation. Several procollagen/collagen isoforms were increased, as well as genes involved in collagen processing and synthesis or in collagen and elastin fibre cross-linking (Lox, Tgm 1 - both validated-). A number of metalloproteases and multiple cytoskeletal genes were increased, especially during the chronic phase.

\section{Discussion}

The main features of the TNBS model of colitis have been well defined. Ethanol causes direct toxic damage to the epithelium, which in turn grants TNBS access to the colonic mucosa, where it acts as a hapten. Although the toxic effect of ethanol is a requisite for TNBS to act effectively, the immunogenic nature of the 'chronic' phase has been unequivocally established by various authors [2325]. Without TNBS, ethanol produces only a short-lived inflammatory reaction that resolves without sequelae and was therefore not of interest in the present study. During the 'chronic' phase, TNBS rat colitis shares a number of features in common with IBD, e.g., transmural inflammation (Crohn's disease only), abnormal ion transport, diarrhoea, fibrosis and abnormal intestinal motility. Furthermore, TNBS rat colitis is amenable to treatment with corticoids, sulfasalazine or tacrolimus, making it an attractive model for the preclinical testing of putative IBD drugs. Our aim was to perform a detailed genomic characterization of the model.

The TNBS colonic inflammatory response was characterized by a marked increase in the expression of multiple genes involved in inflammation/immunity, including cytokines, chemokines, adhesion molecules, eicosanoid- 
Table 2: Genes modulated specifically at day 2

\begin{tabular}{|c|c|c|c|}
\hline Gene symbol & Gene name & FC & SEM \\
\hline Hla-dmb & Major histocompatibility complex, class II, DM beta & 9.13 & 0.47 \\
\hline Fbxl7_predicted & F-box and leucine-rich repeat protein 7 (predicted) & 8.46 & 3.35 \\
\hline Acot 12 & Acyl-CoA thioesterase 12 & 8.19 & 3.28 \\
\hline Prl8a2 & Prolactin family 8 , subfamily a, member 2 & 7.86 & 2.22 \\
\hline Tmodl & Tropomodulin I & 6.66 & 0.79 \\
\hline Sds & Serine dehydratase & 4.57 & 0.71 \\
\hline Adcyap IrI & Adenylate cyclase activating polypeptide I receptor I & 4.56 & 0.54 \\
\hline Sp2 & Sp2 transcription factor & 4.05 & 0.56 \\
\hline Vmd2II_predicted & Vitelliform macular dystrophy 2-like protein I (predicted) & 2.80 & 0.32 \\
\hline Crh & Corticotropin releasing hormone & 2.65 & 0.26 \\
\hline Fzd4 & Frizzled homolog 4 (Drosophila) & 2.64 & 0.14 \\
\hline $\operatorname{lgfbp} 5$ & Insulin-like growth factor binding protein 5 & 2.44 & 0.30 \\
\hline CPG2 & CPG2 protein & 2.32 & 0.08 \\
\hline Lss & Lanosterol synthase & 2.27 & 0.08 \\
\hline Reln & Reelin & 2.10 & 0.17 \\
\hline Atcay_predicted & Ataxia, cerebellar, Cayman type (caytaxin) (predicted) & 2.05 & 0.06 \\
\hline Pik $3 c 2 g$ & Phosphatidylinositol 3-kinase, C2 domain containing, gamma polypeptide & 2.02 & 0.25 \\
\hline Fmo2 & Flavin containing monooxygenase 2 & 1.97 & 0.22 \\
\hline Slcl3a5 & Solute carrier family 13 (sodium-dependent citrate transporter), member 5 & 1.90 & 0.11 \\
\hline XlkdI_predicted & Extra cellular link domain-containing I (predicted) & 1.81 & 0.15 \\
\hline Vps4a & Vacuolar protein sorting $4 \mathrm{a}$ (yeast) & 1.64 & 0.03 \\
\hline Clqbp & Complement component I, q subcomponent binding protein & 1.53 & 0.10 \\
\hline Exosc2_predicted & Exosome component 2 (predicted) & 1.52 & 0.10 \\
\hline Map3k6_predicted & Mitogen-activated protein kinase kinase kinase 6 (predicted) & 1.51 & 0.09 \\
\hline Retnla & Resistin like alpha & 0.05 & 0.03 \\
\hline Csrp2 & Cysteine and glycine-rich protein 2 & 0.10 & 0.03 \\
\hline Dmrtal_predicted & Doublesex and mab-3 related transcription factor like family AI (predicted) & 0.11 & 0.00 \\
\hline $\operatorname{Rax}$ & Retina and anterior neural fold homeobox & 0.13 & 0.04 \\
\hline Ide & Insulin degrading enzyme & 0.14 & 0.02 \\
\hline Opcml & Opioid-binding protein/cell adhesion molecule-like & 0.17 & 0.01 \\
\hline Wdr22_predicted & WD repeat domain 22 (predicted) & 0.18 & 0.05 \\
\hline Noval & Neuro-oncological ventral antigen I & 0.19 & 0.02 \\
\hline Fg20 & Fibroblast growth factor 20 & 0.21 & 0.01 \\
\hline Adh6 & Alcohol dehydrogenase 6 (class V) & 0.22 & 0.02 \\
\hline CpgI & Candidate plasticity gene I & 0.22 & 0.04 \\
\hline Pfkfb2 & 6-phosphofructo-2-kinase/fructose-2,6-biphosphatase 2 & 0.27 & 0.10 \\
\hline Gpha2 & Glycoprotein hormone alpha 2 & 0.31 & 0.01 \\
\hline Mytll & Myelin transcription factor I-like & 0.31 & 0.06 \\
\hline Npffr2 & Neuropeptide FF receptor 2 & 0.33 & 0.07 \\
\hline Csn2 & Casein beta & 0.34 & 0.06 \\
\hline Sybll & Synaptobrevin-like I & 0.34 & 0.04 \\
\hline Efcbp2 & Neuronal calcium binding 2 & 0.40 & 0.06 \\
\hline Cbr3_predicted & Carbonyl reductase 3 (predicted) & 0.41 & 0.03 \\
\hline Alpi & Alkaline phosphatase I, intestinal, defined by SSR & 0.41 & 0.04 \\
\hline Nrxnl & Neurexin I & 0.43 & 0.06 \\
\hline Gp2 & Glycoprotein 2 (zymogen granule membrane) & 0.46 & 0.03 \\
\hline Cd248_predicted & CD248 antigen, endosialin (predicted) & 0.46 & 0.05 \\
\hline Ppfia3 & Protein tyrosine phosphatase, receptor type, f polypeptide (PTPRF), interacting protein (liprin), alpha 3 & 0.59 & 0.02 \\
\hline Zfp580_predicted & Zinc finger protein 580 (predicted) & 0.62 & 0.05 \\
\hline Pttglip & Pituitary tumour-transforming I interacting protein & 0.65 & 0.05 \\
\hline
\end{tabular}

Only annotated genes with a $50 \%$ or higher fold change are included. In all cases the FC at days 5-14 was not significantly different from the control (significance at $P>0.10$ to exclude transcripts not specifically upregulated or downregulated at only day 2 ).

related genes, and a number of effectors and cell markers. There was a dramatic increase in Il1b, Il1a, Il6, Tgfb1 and Tnf and in various chemokine and chemokine receptors. In addition, a nonsignificant increase was observed in the pivotal Il23a and Ifng cytokine genes, which was found to be significant after re-examination using the more sensitive qRT-PCR. Although no protein data are avaliable, it is tempting to speculate that the combined upregulation of 
Table 3: Genes modulated specifically at day 14

\begin{tabular}{|c|c|c|c|}
\hline Gene symbol & Gene name & FC & SEM \\
\hline TbxI5_predicted & T-box I5 (predicted) & 8.00 & 1.74 \\
\hline Trhr & Thyrotropin releasing hormone receptor & 5.67 & 1.26 \\
\hline Ppp3cc & Protein phosphatase 3 (formerly 2B), catalytic subunit, gamma isoform (calcineurin A gamma) & 5.07 & 3.34 \\
\hline Eif2ak3 & Eukaryotic translation initiation factor 2 alpha kinase 3 & 4.92 & 2.25 \\
\hline Hrh3 & Histamine receptor $\mathrm{H} 3$ & 4.35 & 1.34 \\
\hline KIfI5 & Kruppel-like factor 15 & 3.58 & 0.39 \\
\hline Gldc_predicted & Glycine dehydrogenase (decarboxylating; glycine decarboxylase, glycine cleavage system protein P) (predicted) & 3.40 & 1.49 \\
\hline Trdn & Triadin & 3.18 & 0.53 \\
\hline Galr I & Galanin receptor I & 3.15 & 0.04 \\
\hline Mlana_predicted & Melan-A (predicted) & 2.30 & 0.47 \\
\hline Cmal & Chymase I, mast cell & 2.15 & 0.30 \\
\hline Trerfl_predicted & Transcriptional regulating factor I (predicted) & 1.91 & 0.10 \\
\hline Serbpl & Serpine I mRNA binding protein I & 1.85 & 0.22 \\
\hline Ltb4dh & Leukotriene B4 12-hydroxydehydrogenase & 1.78 & 0.24 \\
\hline Fgfl & Fibroblast growth factor I & 1.75 & 0.28 \\
\hline Ace & Angiotensin I converting enzyme & 1.72 & 0.33 \\
\hline Eif4al & Eukaryotic translation initiation factor $4 \mathrm{AI}$ & 1.68 & 0.38 \\
\hline Adar & Adenosine deaminase, RNA-specific & 1.59 & 0.12 \\
\hline Ddbl & Damage-specific DNA binding protein I & 1.57 & 0.05 \\
\hline Mbnl & Muscleblind-like I (Drosophila) & 1.52 & 0.10 \\
\hline Lzts I & Leucine zipper, putative tumour suppressor I & 1.52 & 0.16 \\
\hline Hmgal & High mobility group AT-hook I & 1.51 & 0.13 \\
\hline Apoa5 & Apolipoprotein A-V & 0.08 & 0.01 \\
\hline Strn & Striatin, calmodulin binding protein & 0.09 & 0.05 \\
\hline Olfm3 & Olfactomedin 3 & 0.09 & 0.01 \\
\hline Cdc215 & Cell division cycle 2-like 5 (cholinesterase-related cell division controller) & 0.11 & 0.03 \\
\hline Prom2 & Prominin 2 & 0.11 & 0.02 \\
\hline Snagl_predicted & Sorting nexin associated golgi protein I (predicted) & 0.11 & 0.03 \\
\hline Serpina3m & Serine (or cysteine) proteinase inhibitor, clade $\mathrm{A}$, member $3 \mathrm{M}$ & 0.12 & 0.02 \\
\hline Ankl_predicted & Ankyrin I, erythroid (predicted) & 0.13 & 0.00 \\
\hline Histlhlt & Histone I, hIt & 0.15 & 0.02 \\
\hline Impl & Insulin-like growth factor 2, binding protein I & 0.15 & 0.03 \\
\hline Cacng7 & Calcium channel, voltage-dependent, gamma subunit 7 & 0.16 & 0.05 \\
\hline Rbm9_predicted & RNA binding motif protein 9 (predicted) & 0.19 & 0.03 \\
\hline Drp2 & Dystrophin-related protein 2 A-form splice variant & 0.20 & 0.03 \\
\hline Eif4gI & Eukaryotic translation initiation factor 4 gamma, I & 0.20 & 0.01 \\
\hline Apob & Apolipoprotein B & 0.21 & 0.07 \\
\hline Wtl & Wilms tumor I & 0.23 & 0.02 \\
\hline Pqlc2_predicted & PQ loop repeat containing 2 (predicted) & 0.25 & 0.07 \\
\hline Cnrl & Cannabinoid receptor I (brain) & 0.25 & 0.02 \\
\hline Lmo3 & LIM domain only 3 & 0.26 & 0.03 \\
\hline Bai3_predicted & Brain-specific angiogenesis inhibitor 3 (predicted) & 0.28 & 0.04 \\
\hline Sp3 & $\mathrm{Sp} 3$ transcription factor & 0.31 & 0.02 \\
\hline Apbal & Amyloid beta (A4) precursor protein-binding, family A, member I & 0.32 & 0.03 \\
\hline Kenc3 & Potassium voltage gated channel, Shaw-related subfamily, member 3 & 0.44 & 0.06 \\
\hline Actcl & Actin alpha cardiac I & 0.45 & 0.06 \\
\hline Wntll & Wingless-type MMTV integration site family, member II & 0.47 & 0.09 \\
\hline 112 & Interleukin 2 & 0.50 & 0.08 \\
\hline Galnt2_predicted & UDP-N-acetyl-alpha-D-galactosamine:polypeptide $\mathrm{N}$-acetylgalactosaminyltransferase 2 (predicted) & 0.57 & 0.02 \\
\hline Nrg2 & Neuregulin 2 & 0.60 & 0.04 \\
\hline Cspg4 & Chondroitin sulphate proteoglycan 4 & 0.60 & 0.02 \\
\hline Enth & Enthoprotin & 0.61 & 0.03 \\
\hline Zfp503_predicted & Zinc finger protein 503 (predicted) & 0.66 & 0.02 \\
\hline Rbm3 & RNA binding motif (RNPI, RRM) protein 3 & 0.66 & 0.02 \\
\hline Mpp5_predicted & Membrane protein, palmitoylated 5 (MAGUK p55 subfamily member 5) (predicted) & 0.66 & 0.01 \\
\hline Prgl & Plasticity related gene I & 0.67 & 0.02 \\
\hline Csnkld & Casein kinase I, delta & 0.67 & 0.06 \\
\hline
\end{tabular}

Only annotated genes with a $50 \%$ or higher fold change are included. In all cases the $\mathrm{FC}$ at days $2-7$ was not significantly different from the control (significance at $P>0.10$ to exclude transcripts that were not specifically upregulated or downregulated at only day 14). 


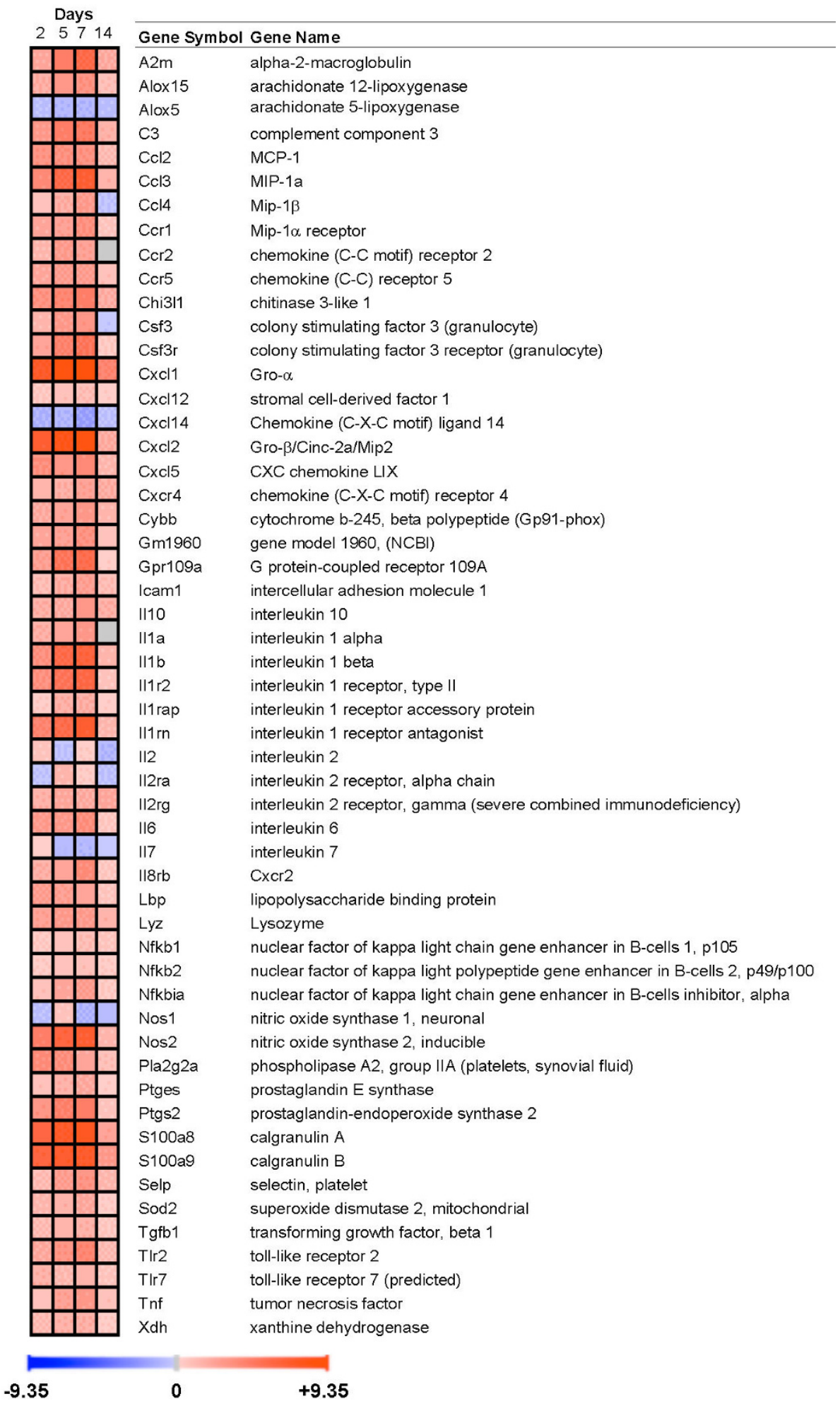

\section{Figure 4}

Behaviour over time of genes involved in inflammation and immune response. Upregulated genes are shown in red and downregulated genes in blue. Gene expression was considered significantly changed by inflammation at $p<0.05$ after analysis of variance followed by Tukey post-hoc tests and Benjamini \& Hochberg false discovery rate correction. 


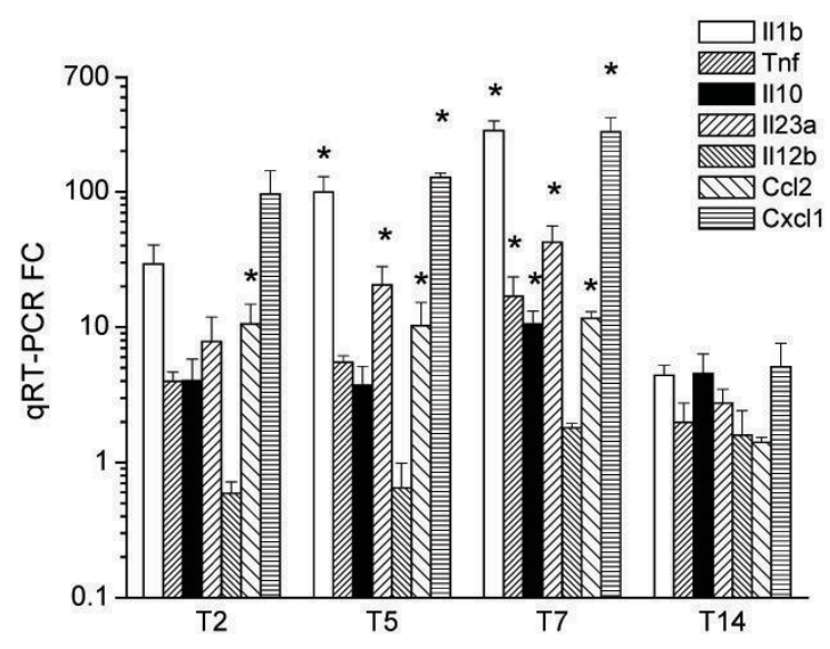

Figure 5

Postgenomic validation of selected inflammation genes by qRT-PCR. * $p<0.05$ vs. control.

Il23a, Il6 and Tgfb 1 are indicative of Th17 induction [26]. In fact, although Il17a was not represented in the microarray, qRT-PCR findings showed an increase in the mRNA levels (data not shown), suggesting the involvement of Th17 cells in rat TNBS colitis. A contribution of Th1 cells is also likely in view of the Ifng upregulation and lack of Il4 changes, although Il12a and Il12b were not augmented. Our group [27] and other authors $[28,29]$ previously reported an increase in the IFN- $\gamma$ or IFN- $\gamma / \mathrm{IL}-4$ protein ratio in this model. A staggering increase was observed in some of the genes, e.g. S100a9/S100a8, suggesting that they may be highly sensitive markers to follow intestinal inflammation, as previously observed in humans [30,31]. These genes encode proteins expressed by macrophages and neutrophils and are involved in bacterial defence, chemotaxis and signalling $[32,33]$.

Analysis of the microarray data offered insights into the nature of the inflammatory infiltrate. TNBS colitis was previously characterized at this level [25]. In brief, macrophages and neutrophils are initially recruited to the colonic mucosa and submucosa, followed by a more predominant role of lymphocytes in later stages of colitis, which are characterized by progressive healing, reepithelialization, crypt enlargement and prominent fibrosis [25]. The predominance of neutrophils/macrophages in the inflammatory response was confirmed in our study by the global increase in gene markers of these cell types and the absence of effects on $\mathrm{B}, \mathrm{T}$ and NK cells (at significance level of $\mathrm{p}<0.05$ ). It should be noted that the sample used for genomic analysis did not include lymphoid follicles, in which lymphocytes accumulate in this model [25], which explains the lack of a significant increase. However, gene ontology analysis indicated that lymphocyte differentiation was already prominent at day 5 .

Our data also revealed important changes that were not directly linked to inflammation/immunity. Thus, marked alterations were found in metabolism-related genes, indicating a reduced functionality of numerous biochemical pathways, including glycolysis, purine biosynthesis, Krebs cycle, cholesterol biosynthesis and transport, fatty acid biosynthesis and respiratory chain. Taken together, these data demonstrate a decrease in biosynthesis of macromolecules, an increase in catabolism, and a decrease in aerobic and anaerobic respiration. Therefore, mucosal cells may be have inadequate energy resources during the inflammatory response. Similar changes have been reported in IBD patients [34] and in experimental colitis [35].

A number of genes encoding ion transporters were affected by TNBS colitis, including: Atp1a1, encoding the catalytic subunit of the $\mathrm{Na}^{+} / \mathrm{K}^{+}$pump; Scnn1a, encoding the alpha polypeptide of the epithelial sodium channel; Nhe1, encoding the housekeeping $\mathrm{Na}^{+} / \mathrm{H}^{+}$exchanger; and Slc12a2, encoding Nkcc2, the $\mathrm{Na}^{+} / \mathrm{K}^{+} / \mathrm{Cl}^{-}$cotransporter. These were generally downregulated, as were the transporters involved in $\mathrm{NaCl}$ absorption, e.g., Nhe2, Nhe3, and Slc26a3. However, Cftr was unchanged. These modifications are consistent with severe alterations of ionic transport, as demonstrated in IBD and animal models $[17,36,37]$.

A striking finding of our analysis was the vast number of upregulated genes involved in tissue remodelling in TNBS colitis, generally during the chronic phase, as indicated by the gene ontology analysis. The chronic phase is characterized by mucosal wound healing and submucosal fibrosis and by the scarring and deposition of excess muscular tissue, extending through day 14 and eventually leaving sequelae [5]. These features are often detectable by the naked eye as colonic shortening, deformation and rigidity. Two features are related to the intestinal fibrosis suffered by IBD patients: an increase in collagen synthesis by smooth muscle cells, fibroblasts and myofibroblasts, and an increase in muscle layer thickness. IGFBP-5 expression is known to increase in ulcerative colitis, while IGF-1 and TGF- $\beta_{1}$ expression is known to increase in both ulcerative colitis and Crohn's disease [38,39]. These molecules have been related to extracellular matrix remodelling and may therefore be relevant to the fibrosis observed in IBD. Our results are in agreement with these IBD findings, showing an increase in Igf1, Igfbp5 and Tgfb1 expression in the inflamed colon. Hence, the TNBS model may be appropriate for the study of molecular mechanisms implicated in the development of fibrosis in intestinal inflammation. In addition, expressions of procollagen/collagen genes, most 


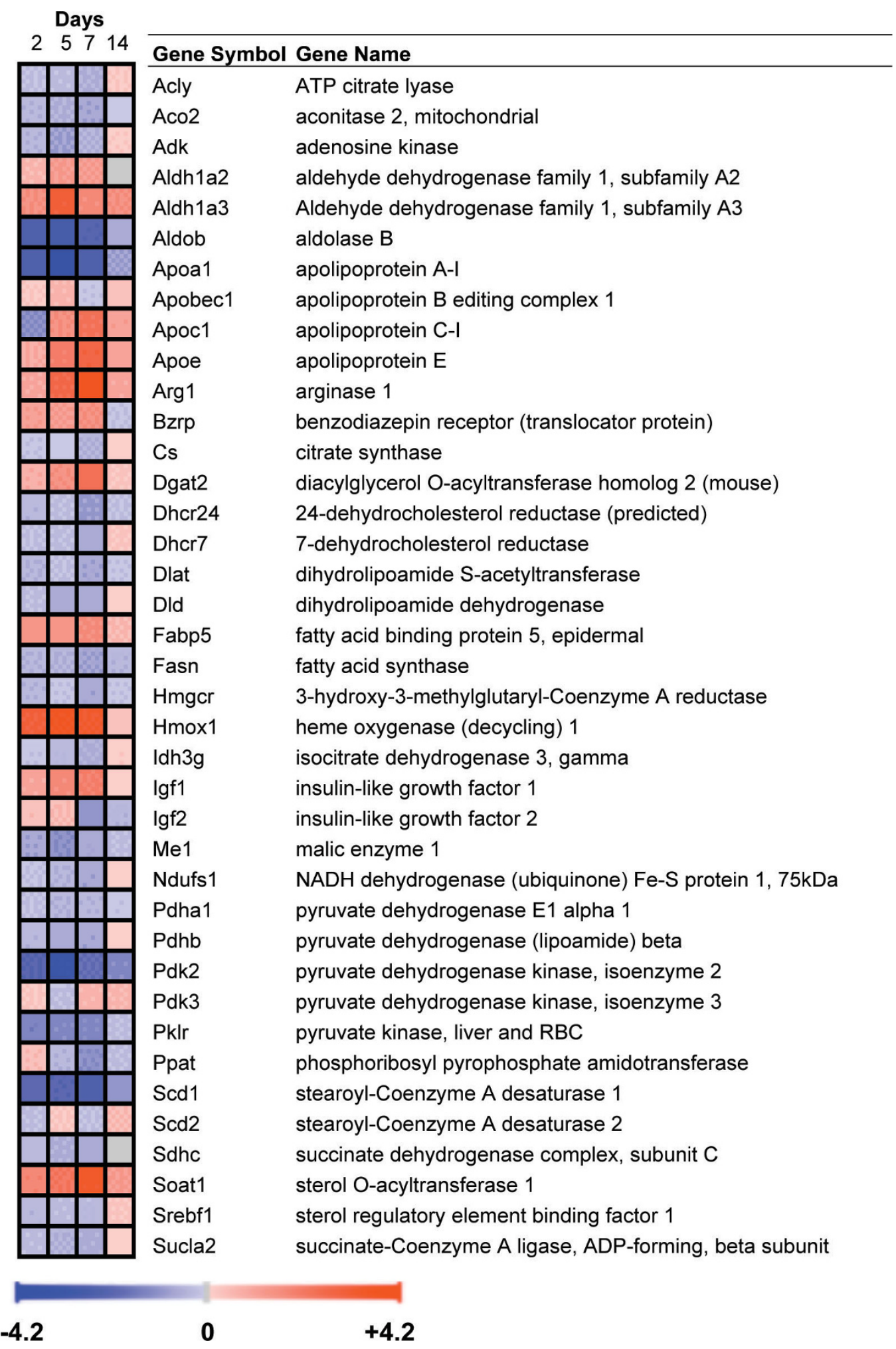

Figure 6

Behaviour over time of genes involved in metabolism. Upregulated genes are shown in red and downregulated genes in blue. Gene expression was considered significantly changed by inflammation at $p<0.05$ after analysis of variance followed by Tukey post-hoc tests and Benjamini \& Hochberg false discovery rate correction. 


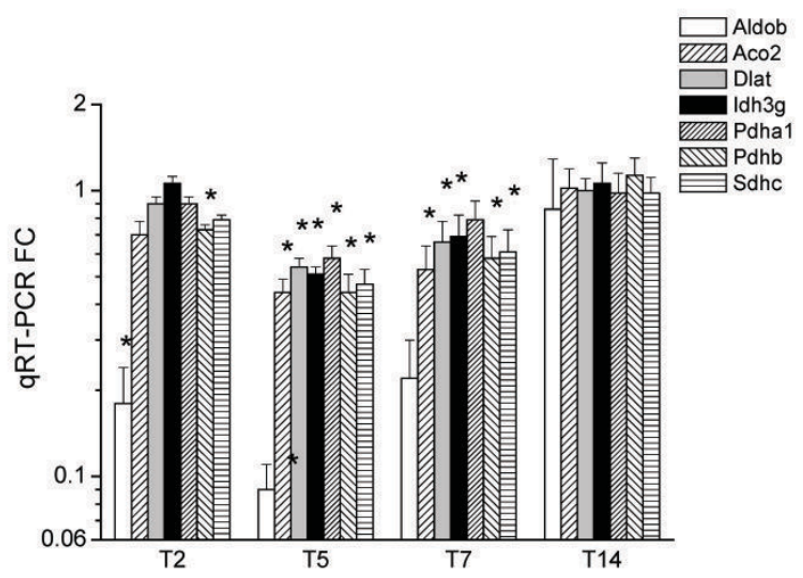

Figure 7

Postgenomic validation of selected metabolic genes by qRT-PCR. *P $<0.05$ vs. control.

notably Tgm1, and of several enzymes related to collagen processing were increased in the TNBS colitic animals.

Our results include some intriguing findings, including: the severe repression of nuclear receptors $\mathrm{Nr} 1 \mathrm{~d} 1$ and Nr1d2, involved in circadian expression patterns and recently shown to be regulated by heme [40]; the synthesis and marked upregulation of Tg in the inflamed colon; and the downregulation of the thyroid receptor. Further experiments are warranted to clarify the role of these changes in colonic inflammation.

We were especially interested in establishing a correlation between the known characteristics of the model and the time course of gene expression. Because the time points selected cover all stages of the TNBS-induced inflammatory response, from acute $(2 \mathrm{~d})$ to chronic (5-7 d) and healing/recovery (14 d) phases, we expected to find substantial differences in the pattern of expression. For instance, genes involved in inflammation/immunity and tissue regeneration were expected to predominate in the early and late stages, respectively. However, the vast majority of transcripts followed a common trend, namely a change of expression that was maximal at days 5 and 7, when colitis is most prominent, and was normal (or almost normal) at day 14 . Hence, there is a close correlation between the pathological features of TNBS colitis and the changes observed in the transcriptome. The genes that were up- or downregulated only at days 2 or 14 did not conform to any specific category. Some of the transcripts involved are of interest. Thus, Retnla, which encodes resistin-like alpha, which is dramatically repressed soon after colitis induction, may be involved in monocyte activation, as is the beta isoform [41]. Both Ace and Cma1, which encode enzymes with angiotensin I cleaving capac- ity, are induced specifically at day 14 . Some specific receptors involved in cellular signalling are differentially regulated, such as Galr1, Hrh3, Npffr2 and Cnr1. Further analysis is warranted to explore the implications of these findings.

Despite using a technical approach (triplicate samples per time point) that meets or surpasses common standards in genomic studies, we carried out more than 1100 qRT-PCR determinations in 15 additional samples for a posteriori data validation. As expected, the overall correlation was excellent. In some cases, microarray analysis appeared to be less prone to pick up statistically significant variations, i.e. it was less sensitive than qRT-PCR. The fact that we examined four different time points adds to the complexity of the analysis, since a marked change at one time point may not be enough in many cases to reach significance in the ANOVA. Further validation is provided by the fact that the changes (or lack thereof) observed in many genes, including Il1b, Il1rn, Cftr, Tnf, Alpl, Alpi, Ifng, Il4, Il6, Pgts2, Nos2 and Ccl2, among many others, are in line with previous observations from our own group, either at the RNA or protein level $[12,18,27]$.

Previous studies have examined changes in the transcriptome in intestinal inflammation, especially in mouse colitis elicited by TNBS and other manoeuvres [6-10]. These studies are somewhat limited because they either use small microarrays, examine animals shortly after colitis induction (consistent with acute but not chronic colitis), offer limited or no postgenomic validation or use longitudinal tissue samples. One of these studies addressed the time course of gene expression, but it studied recovery from repeated TNBS challenges [9]. In general, the changes in gene expression documented in the present study are much stronger and wider than those found in previous reports. For example, 175 genes were differentially expressed in the above study in compared to the thousands of genes in our investigation. On the other hand, there have been several human IBD microarray studies [30,31,42-47], which have detected some key gene expression changes associated with human intestinal inflammation, including some specifically linked to either ulcerative colitis or Crohn's disease [47]. However, it is poorly understood how genomic data are related to IBD pathology and therapy, partly because of the variability inherent to human studies and partly because of methodological differences [48]. For instance, the most important source of variation in gene expression measurement (54\%) is the microarray platform itself [49], and all of the above studies used different arrays. There are also differences in design and especially in sample selection, i.e., individual vs. pooled or mucosal vs. full thickness. Nevertheless, there are some similarities with the rat TNBS model, including increases in Chi3l1, Mmp3, 10 and 12, 


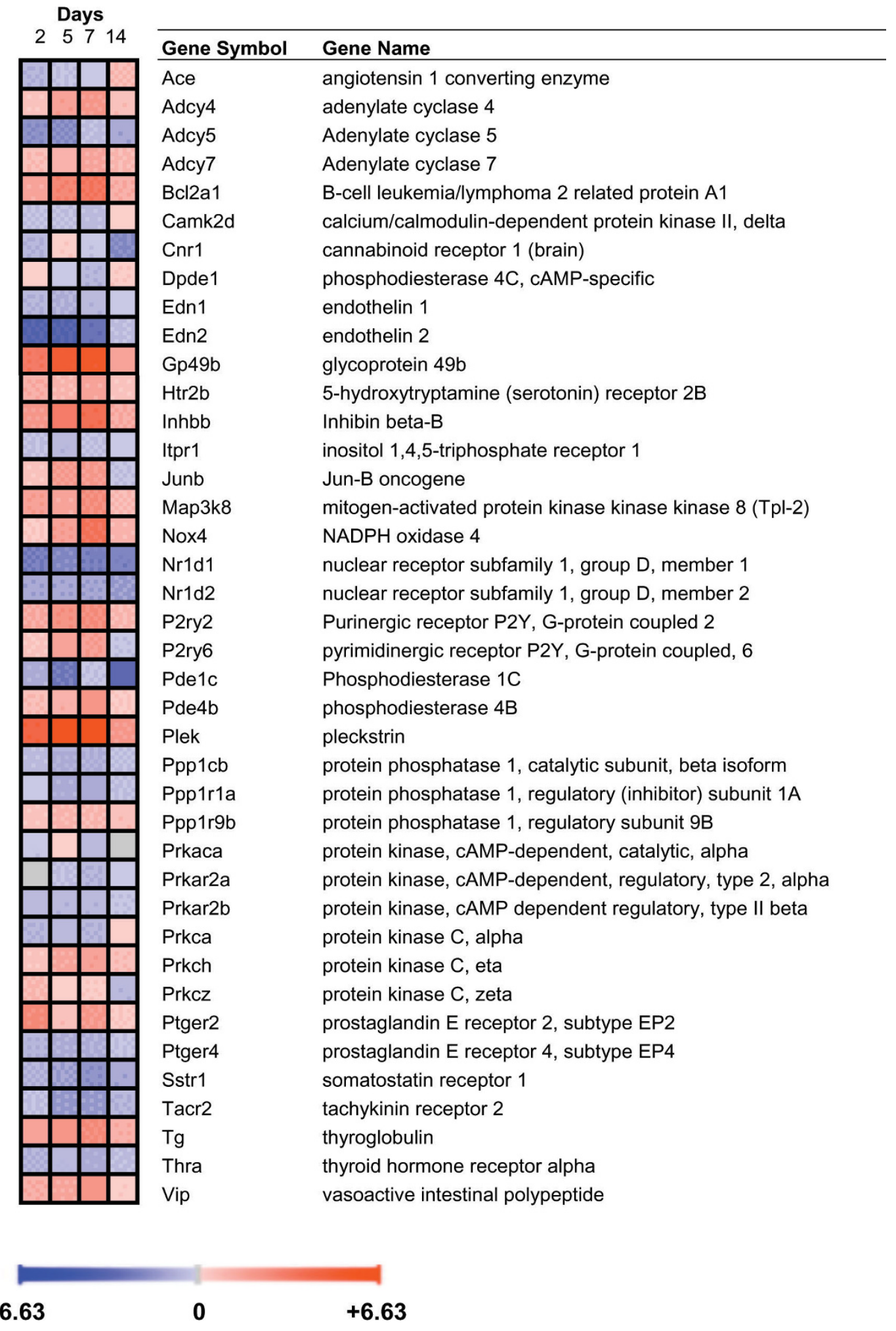

\section{Figure 8}

Behaviour over time of genes involved in cell signalling. Upregulated genes are shown in red and downregulated genes in blue. Gene expression was considered significantly changed by inflammation at $p<0.05$ after analysis of variance followed by Tukey post-hoc tests and Benjamini \& Hochberg false discovery rate correction. 


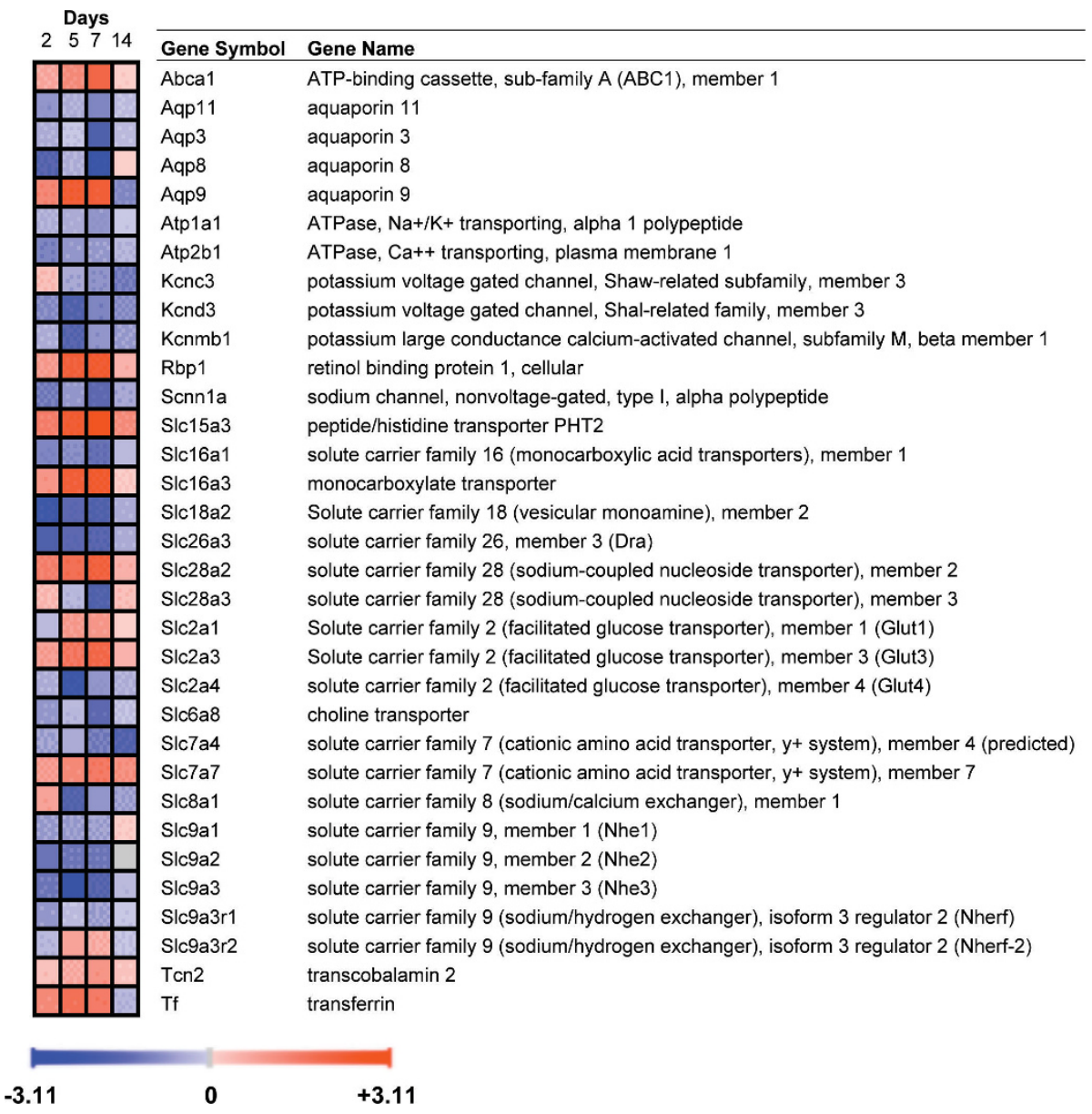

Figure 9

Behaviour over time of genes involved in transport. Upregulated genes are shown in red and downregulated genes in blue. Gene expression was considered significantly changed by inflammation at $p<0.05$ after analysis of variance followed by Tukey post-hoc tests and Benjamini \& Hochberg false discovery rate correction.

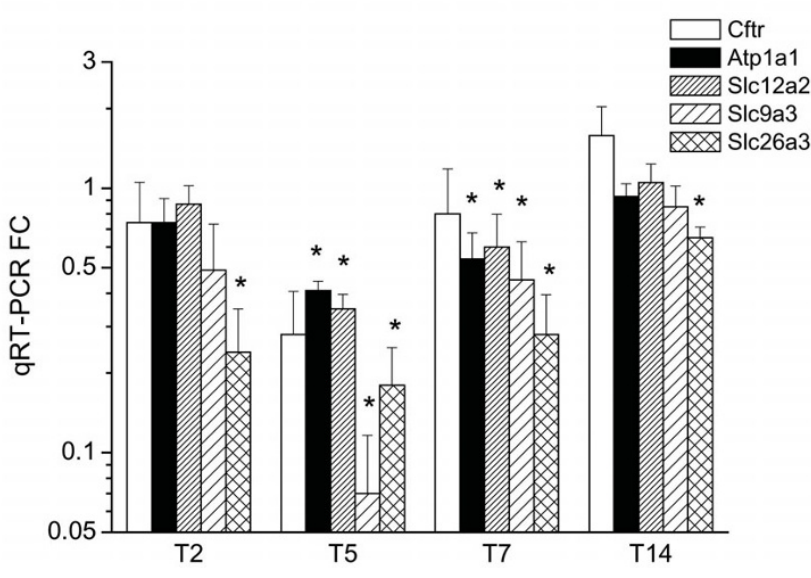

Figure 10

Postgenomic validation of selected ion transport genes by qRT-PCR. $* P<0.05$ vs. control.
Apoe, S100a8, Ltb, Sod2, Cxcl1, Cxcl2, Il6 and many other genes.

\section{Conclusion}

We have characterized the rat TNBS model of IBD at the genomic level, obtaining novel data on individual genes, metabolic pathways and biological functions that are altered during colitis. These findings establish a basis for further mechanistic studies on drug action and research into the pathophysiology of intestinal inflammation. The full genomic database will serve as a reference standard for all future investigations using this model and for comparisons with other animal models of colitis, an approach that is currently being applied in our laboratory.

\section{Abbreviations}

IBD: inflammatory bowel disease; IL: interleukin; qRTPCR: quantitative real time PCR; TNBS: trinitrobenzenesulphonic acid. 


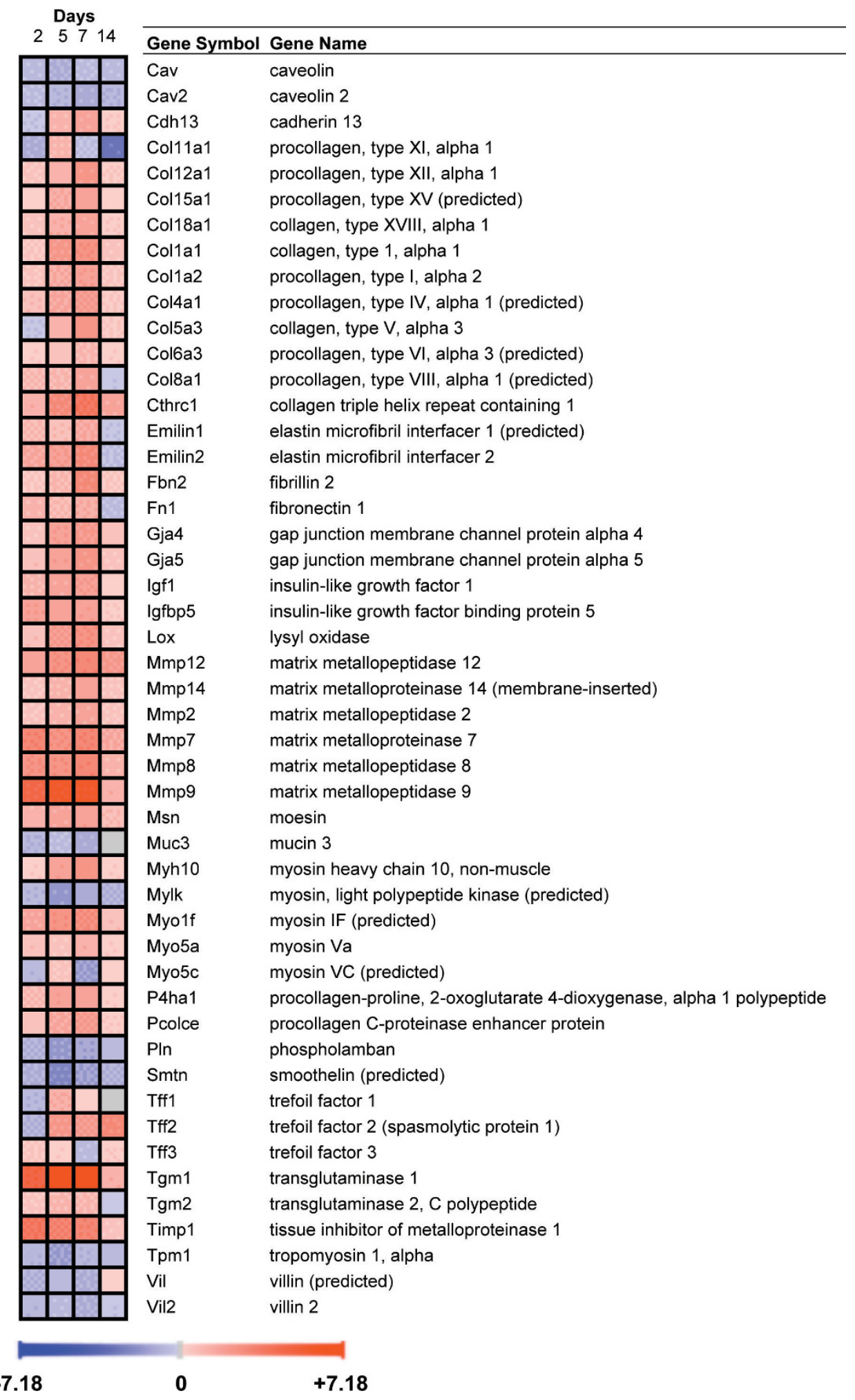

Figure I I

Behaviour over time of genes involved in tissue remodelling. Upregulated genes are shown in red and downregulated genes in blue. Gene expression was considered significantly changed by inflammation at $p<0.05$ after analysis of variance followed by Tukey post-hoc tests and Benjamini \& Hochberg false discovery rate correction. 


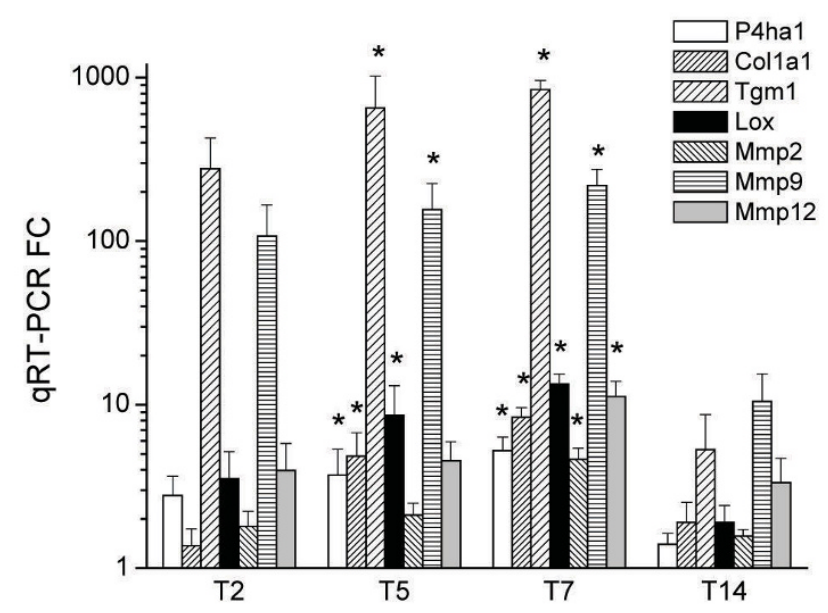

Figure 12

Postgenomic validation of selected tissue remodeling genes by qRT-PCR. $* P<0.05$ vs. control.

\section{Authors' contributions}

FSMLH and OMA conducted the animal experiments, coordinated the bioinformatic analysis of the microarray and qRT-PCR data and drafted the manuscript. FSMLH, OMA, MDS and AZ conceived the study. All authors contributed to the interpretation of the data and have read and approved the final manuscript.

\section{Acknowledgements}

The authors acknowledge the technical help of Dietmar Fernández and David Arteta from Progenika Biopharma and the assistance of the European Bioinformatics Institute. This study was supported by the Instituto de Investigación Carlos III (PI05I65I, PI05I625), the Spanish Junta de Andalucía (ARM/LD 43035), the Ministry of Industry, and Fundación Genoma España.

\section{References}

I. Sands BE: Inflammatory bowel disease: past, present, and future. J Gastroenterol 2007, 42:16-25.

2. Jurjus AR, Khoury NN, Reimund JM: Animal models of inflammatory bowel disease. J Pharmacol Toxicol Methods 2004, 50:81-92.

3. Neurath M, Fuss I, Strober W: TNBS-colitis. Int Rev Immunol 2000, 19:51-62.

4. Sanchez de Medina F, Galvez J, Romero JA, Zarzuelo A: Effect of quercitrin on acute and chronic experimental colitis in the rat. J Pharmacol Exp Ther 1996, 278:771-779.

5. Morris GP, Beck PL, Herridge MS, Depew WT, Szewczuk MR, Wallace JL: Hapten-induced model of chronic inflammation and ulceration in the rat colon. Gastroenterology 1989, 96:795-803.

6. Yamamoto S, Isuzugawa K, Takahashi $\mathrm{Y}$, Murase $\mathrm{Y}$, Iwata M, Arisawa T, Nakano H, Nishimura N, Yamato S, Ohta M, Ina K, Murata T, Hori $M$, Ozaki H, Imakawa $K$ : Intestinal gene expression in TNBS treated mice using genechip and subtractive cDNA analysis: implications for Crohn's disease. Biol Pharm Bull 2005, 28:2046-2053.

7. Abad C, Juarranz Y, Martinez C, Arranz A, Rosignoli F, Garcia-Gomez M, Leceta J, Gomariz RP: cDNA array analysis of cytokines, chemokines, and receptors involved in the development of TNBS-induced colitis: homeostatic role of VIP. Inflamm Bowel Dis 2005, I I:674-664.

8. te Velde AA, de Kort F, Sterrenburg E, Pronk I, ten Kate FJ, Hommes DW, van Deventer SJ: Comparative analysis of colonic gene expression of three experimental colitis models mimicking inflammatory bowel disease. Inflamm Bowel Dis 2007, I 3:325-330.

9. Wu F, Chakravarti S: Differential expression of inflammatory and fibrogenic genes and their regulation by NF-kappaB inhibition in a mouse model of chronic colitis. J Immunol 2007, | 79:6988-7000.

10. Rivera E, Flores I, Rivera E, Appleyard CB: Molecular profiling of a rat model of colitis: validation of known inflammatory genes and identification of novel disease-associated targets. Inflamm Bowel Dis 2006, I 2:950-966.

II. Gonzalez R, Sanchez de Medina F, Martinez-Augustin O, Nieto A, Galvez J, Risco S, Zarzuelo A: Anti-inflammatory effect of diosmectite in hapten-induced colitis in the rat. $\mathrm{Br} J$ Pharmacol 2004, I 41:951-960.

12. Daddaoua A, Puerta V, Zarzuelo A, Suarez MD, Sanchez de Medina F, Martinez-Augustin O: Bovine glycomacropeptide is anti-inflammatory in rats with hapten-induced colitis. J Nutr 2005, 135:1164-1170.

13. Krawisz JE, Sharon P, Stenson WF: Quantitative assay for acute intestinal inflammation based on myeloperoxidase activity. Assessment of inflammation in rat and hamster models. Gastroenterology 1984, 87: I344-1350.

14. Salomonis N, Hanspers K, Zambon AC, Vranizan K, Lawlor SC, Dahlquist KD, Doniger SW, Stuart J, Conklin BR, Pico AR: GenMAPP 2: new features and resources for pathway analysis. BMC Bioinformatics 2007, 8:217.

15. Doniger SW, Salomonis N, Dahlquist KD, Vranizan K, Lawlor SC, Conklin BR: MAPPFinder: using Gene Ontology and GenMAPP to create a global gene-expression profile from microarray data. Genome Biol 2003, 4:R7.

16. Brazma A, Hingamp P, Quackenbush J, Sherlock G, Spellman P Stoeckert C, Aach J, Ansorge W, Ball CA, Causton HC, Gaasterland T, Glenisson P, Holstege FC, Kim IF, Markowitz V, Matese JC, Parkinson H, Robinson A, Sarkans U, Schulze-Kremer S, Stewart J, Taylor R, Vilo J, Vingron M: Minimum information about a microarray experiment (MIAME)-toward standards for microarray data. Nat Genet 200I, 29:365-37I.

17. Sanchez de Medina F, Perez R, Martinez-Augustin O, Gonzalez R, Lorente MD, Galvez J. Zarzuelo A: Disturbances of colonic ion secretion in inflammation: role of the enteric nervous system and cAMP. Pflugers Arch 2002, 444:378-388.

18. Sanchez de Medina F, Martinez-Augustin O, Gonzalez R, Ballester I, Nieto A, Galvez J, Zarzuelo A: Induction of alkaline phosphatase in the inflamed intestine: a novel pharmacological target for inflammatory bowel disease. Biochem Pharmacol 2004 68:2317-2326.

19. Berbee JF, Havekes LM, Rensen PC: Apolipoproteins modulate the inflammatory response to lipopolysaccharide. J Endotoxin Res 2005, I I:97-103.

20. Bryceson YT, Torgersen KM, Inngjerdingen M, Berg SF, Hoelsbrekken $\mathrm{SE}$, Fossum S, Dissen E: The rat orthologue to the inhibitory receptor gp49B is expressed by neutrophils and monocytes, but not by NK cells or mast cells. Eur J Immunol 2005, 35:1230-1239.

21. Brumell JH, Howard JC, Craig K, Grinstein S, Schreiber AD, Tyers M: Expression of the protein kinase $C$ substrate pleckstrin in macrophages: association with phagosomal membranes. J Immunol 1999, 163:3388-3395.

22. Rotoli BM, Bussolati O, Sala R, Barilli A, Talarico E, Gazzola GC Dall'Asta V: INFgamma stimulates arginine transport through system $y+L$ in human monocytes. FEBS Lett 2004, 57 I: 177- I81.

23. Allgayer H, Deschryver K, Stenson WF: Treatment with 16, 16'dimethyl prostaglandin E2 before and after induction of colitis with trinitrobenzenesulfonic acid in rats decreases inflammation. Gastroenterology 1989, 96:1290-1300.

24. Appleyard CB, Wallace JL: Reactivation of hapten-induced colitis and its prevention by anti-inflammatory drugs. Am J Physio 1995, 269:GI I9-GI25.

25. Palmen MJ, Dieleman LA, Ende MB van der, Uyterlinde A, Pena AS, Meuwissen SG, van Rees EP: Non-lymphoid and lymphoid cells in acute, chronic and relapsing experimental colitis. Clin Exp Immunol 1995, 99:226-232.

26. Spencer JP, Chowrimootoo G, Choudhury R, Debnam ES, Srai SK, Rice-Evans C: The small intestine can both absorb and glucuronidate luminal flavonoids. FEBS Lett 1999, 458:224-230. 
27. Pérez-Navarro R, Ballester I, Zarzuelo A, Sánchez de Medina F: Disturbances in epithelial ionic secretion in different experimental models of colitis. Life Sciences 2005, 76: I489-I50I.

28. Stasi MA, Ruggiero V, Ursillo A, Taurelli R, Agliano M, Weber E, Lorenzoni P, Sorrentino V, Pacifici L, Carminati P: Ameliorating effects of the immunomodulator 3-(2-ethylphenyl)-5-(3methoxyphenyl)- I H-I,2,4-triazole in an experimental model of colitis in the rat. Eur J Pharmacol 2004, 494:263-272.

29. Sun FF, Lai PS, Yue G, Yin K, Nagele RG, Tong DM, Krzesicki RF, Chin JE, Wong PY: Pattern of cytokine and adhesion molecule mRNA in hapten-induced relapsing colon inflammation in the rat. Inflammation 200I, 25:33-45.

30. Lawrance IC, Fiocchi C, Chakravarti S: Ulcerative colitis and Crohn's disease: distinctive gene expression profiles and novel susceptibility candidate genes. Hum Mol Genet 200I, I 0:445-456.

31. Dieckgraefe BK, Stenson WF, Korzenik JR, Swanson PE, Harrington $C A$ : Analysis of mucosal gene expression in inflammatory bowel disease by parallel oligonucleotide arrays. Physiol Genomics 2000, 4: I-II.

32. Raquil MA, Anceriz N, Rouleau P, Tessier PA: Blockade of Antimicrobial Proteins SI00A8 and SI00A9 Inhibits Phagocyte Migration to the Alveoli in Streptococcal Pneumonia. J Immunol 2008, 180:3366-3374.

33. Gebhardt C, Riehl A, Durchdewald M, Nemeth J, Furstenberger G, Muller-Decker K, Enk A, Arnold B, Bierhaus A, Nawroth PP, Hess J, Angel P: RAGE signaling sustains inflammation and promotes tumor development. J Exp Med 2008, 205:275-285.

34. Heimerl S, Moehle C, Zahn A, Boettcher A, Stremmel W, Langmann T, Schmitz G: Alterations in intestinal fatty acid metabolism in inflammatory bowel disease. Biochim Biophys Acta 2006 I 762:34|-350.

35. Melgar S, Bjursell M, Gerdin AK, Svensson L, Michaelsson E, BohloolyY M: Mice with experimental colitis show an altered metabolism with decreased metabolic rate. Am J Physiol Gastrointest Liver Physiol 2007, 292:GI65-GI72.

36. Sugi $K$, Musch MW, Field M, Chang EB: Inhibition of $\mathbf{N a + , ~ K + - ~}$ ATPase by interferon gamma down-regulates intestinal epithelial transport and barrier function. Gastroenterology 200I I 20: 1393-1403.

37. Martinez-Augustin O, Romero-Calvo I, Suarez MD, Zarzuelo A, Sanchez de Medina F: Molecular bases of impaired water and ion movements in inflammatory bowel diseases. Inflammatory Bowel Diseases 2008. DOI 10.1002/ibd.20579

38. Zimmermann EM, Li L, Hou YT, Mohapatra NK, Pucilowska JB: Insulin-like growth factor I and insulin-like growth factor binding protein $\mathbf{5}$ in Crohn's disease. Am J Physiol Gastrointest Liver Physiol 2001, 280:GI022-GI029.

39. Lawrance IC, Maxwell L, Doe W: Inflammation location, but not type, determines the increase in TGF-betal and IGFexpression and collagen deposition in IBD intestine. Inflamm Bowel Dis 2001, 7:16-26.

40. Raghuram S, Stayrook KR, Huang P, Rogers PM, Nosie AK, McClure DB, Burris LL, Khorasanizadeh S, Burris TP, Rastinejad F: Identification of heme as the ligand for the orphan nuclear receptors REV-ERBalpha and REV-ERBbeta. Nat Struct Mol Biol 2007, |4:1207-1213

41. McVay LD, Keilbaugh SA, Wong TM, Kierstein S, Shin ME, Lehrke M, Lefterova MI, Shifflett DE, Barnes SL, Cominelli F, Cohn SM, Hecht G, Lazar MA, Haczku A, Wu GD: Absence of bacterially induced RELMbeta reduces injury in the dextran sodium sulfate model of colitis. J Clin Invest 2006, I | 6:29|4-2923.

42. Uthoff SM, Eichenberger MR, Lewis RK, Fox MP, Hamilton CJ, McAuliffe TL, Grimes HL, Galandiuk S: Identification of candidate genes in ulcerative colitis and Crohn's disease using cDNA array technology. Int J Oncol 2001, 19:803-810.

43. Heller RA, Schena M, Chai A, Shalon D, Bedilion T, Gilmore J, Woolley DE, Davis RW: Discovery and analysis of inflammatory disease-related genes using cDNA microarrays. Proc Natl Acad Sci USA 1997, 94:2150-2155.

44. Dooley TP, Curto EV, Reddy SP, Davis RL, Lambert GW, Wilborn $\mathrm{TW}$, Elson $\mathrm{CO}$ : Regulation of gene expression in inflammatory bowel disease and correlation with IBD drugs: screening by DNA microarrays. Inflamm Bowel Dis 2004, I 0: I- I4.

45. Langmann T, Moehle C, Mauerer R, Scharl M, Liebisch G, Zahn A, Stremmel W, Schmitz G: Loss of detoxification in inflammatory bowel disease: dysregulation of pregnane $X$ receptor target genes. Gastroenterology 2004, 1 27:26-40.

46. Costello CM, Mah N, Hasler R, Rosenstiel P, Waetzig GH, Hahn A Lu T, Gurbuz Y, Nikolaus S, Albrecht M, Hampe J, Lucius R, Kloppel $G$, Eickhoff H, Lehrach H, Lengauer T, Schreiber S: Dissection of the inflammatory bowel disease transcriptome using genome-wide cDNA microarrays. PLoS Med 2005, 2:el99.

47. Wu F, Dassopoulos T, Cope L, Maitra A, Brant SR, Harris ML, Bayless TM, Parmigiani G, Chakravarti S: Genome-wide gene expression differences in Crohn's disease and ulcerative colitis from endoscopic pinch biopsies: insights into distinctive pathogenesis. Inflamm Bowel Dis 2007, 13:807-82I.

48. Csillag C, Nielsen OH, Borup R, Nielsen FC: Microarrays and Crohn's disease: collecting reliable information. Scand J Gastroenterol 2005, 40:369-377.

49. Bammler T, Beyer RP, Bhattacharya S, Boorman GA, Boyles A, Bradford BU, Bumgarner RE, Bushel PR, Chaturvedi K, Choi D, Cunningham ML, Deng S, Dressman HK, Fannin RD, Farin FM, Freedman JH, Fry RC, Harper A, Humble MC, Hurban P, Kavanagh TJ, Kaufmann WK, Kerr KF, Jing L, Lapidus JA, Lasarev MR, Li J, Li YJ, Lobenhofer EK, Lu X, Malek RL, Milton S, Nagalla SR, O'malley JP, Palmer VS, Pattee P, Paules RS, Perou CM, Phillips K, Qin LX, Qiu Y, Quigley SD, Rodland M, Rusyn I, Samson LD, Schwartz DA, Shi Y, Shin JL, Sieber SO, Slifer S, Speer MC, Spencer PS, Sproles DI, Swenberg JA, Suk WA, Sullivan RC, Tian R, Tennant RW, Todd SA, Tucker CJ, Van Houten $B$, Weis BK, Xuan S, Zarbl H: Standardizing global gene expression analysis between laboratories and across platforms. Nat Methods 2005, 2:351-356.

Publish with Bio Med Central and every scientist can read your work free of charge

"BioMed Central will be the most significant development for disseminating the results of biomedical research in our lifetime. "

Sir Paul Nurse, Cancer Research UK

Your research papers will be:

- available free of charge to the entire biomedical community

- peer reviewed and published immediately upon acceptance

- cited in PubMed and archived on PubMed Central

- yours - you keep the copyright
BioMedcentral 